\title{
Diabetes Dictating Policy: An Editorial Commemorating World Health Day 2016
}

\author{
Amirhossein Takian $^{1,2,3}$, Sara Kazempour-Ardebili ${ }^{4^{*}}$
}

Article History:

Received: 19 April 2016 Accepted: 11 June 2016 ePublished: 18 June 2016

View Video Summary

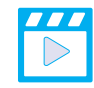

*Correspondence to:

Sara Kazempour-Ardebili

Email: s.kazempour@endocrine.ac.ir
$\mathrm{D}$ iabetes is a leading public health concern worldwide, and despite years of research and development on diabetes care and prevention, it is still one of the fastest growing conditions in the world; according to the World Health Organization (WHO) the number of people living with diabetes has quadrupled since 1980 and in 2014 there were an estimated 422 million adults with diabetes in the world. ${ }^{1}$ This is a staggering statistic; to better put this number into perspective, diabetes can be addressed as the third most populated country in the world, after China and India. ${ }^{2}$ The rise in worldwide diabetes prevalence has mirrored the rise in overweight and obesity, with a greater increase in these conditions in low- and middle-income countries. ${ }^{3}$ Unfortunately, the WHO Eastern Mediterranean Region, to which Iran belongs to, is now the world leader in increasing diabetes prevalence. ${ }^{4}$

But why is diabetes important? Because it is a lifelong condition, with no established definite cure, has costly short- and long-term complications, can lead to premature death and disability. In other words, it is very expensive. There are direct medical costs, which include expenditure on prevention, treatment and management of complications. These encompass outpatient, inpatient, emergency care, longterm care, medications and medical devices. There are also indirect costs, which are associated with loss of productivity, premature death and disability and a negative impact on the countries' gross domestic product (GDP). While calculation of indirect health costs is difficult and quite complex, the annual direct health costs associated with diabetes has been estimated in a recent meta-analysis to be US $\$ 825$ billion globally. 5,6

All of this is a testament to the need for global action where diabetes is concerned. The importance of addressing the problem of diabetes has been emphasized by the WHO in naming the 2016 World Health Day 'Beat Diabetes.' This is a campaign that aims to increase awareness about the rising prevalence of diabetes and trigger a specific set of actions for combating diabetes. The WHO has also launched its first Global Diabetes Report on this day, a document that outlines not only the importance of battling diabetes, but also a framework for surveillance, prevention, and effective management of the condition.

Diabetes is one of four non-communicable diseases (NCDs) targeted in the 2011 Political Declaration on the Prevention and Control of NCDs (the other three are cardiovascular disease, cancer, and chronic respiratory diseases), which recognizes the need for population-wide, multisectoral interventions to prevent and reduce NCDs. In 2013, a comprehensive Global Monitoring Framework was developed and adopted by the World Health Assembly (WHA), which included nine voluntary targets to be reached by member states 2025: a 25\% reduction in mortality caused by cardiovascular disease, diabetes, cancer, and chronic respiratory diseases, $10 \%$ reduction in alcohol abuse, $10 \%$ reduction in physical inactivity, 30\% reduction in salt intake, 30\% reduction in smoking, $25 \%$ reduction in high blood pressure or halt the increase in high blood pressure (depending on national circumstances), halt the rise in diabetes and obesity, expansion of preventive cardiovascular treatment (including glycemic control) to at least $50 \%$ of eligible population and $80 \%$ availability of affordable basic technologies and essential medicines for the treatment of the aforementioned four NCDs. ${ }^{7}$ The framework was accompanied by the WHO NCD Global Action Plan, endorsed by the 66th World Health Assembly, which provides guidance on policies that help achieve the ambitious targets set in the framework. ${ }^{8}$

NCDs, including diabetes, have also been recognized as a threat to sustainable development and thus, addressed in the 2030 Agenda for Sustainable Development, adopted by world leaders at the 2015 United Nations Development Summit. The 
Agenda includes 17 Sustainable Development Goals (SDGs), the third of which addresses good health and well-being for all. Among the objectives set for this goal, member states have committed to 'reduce premature mortality from NCDs through prevention and treatment by one third by 2030,' which mirrors the first voluntary target set in the Global Monitoring Framework for NCDs. By recognizing NCDs as an obstacle for sustainable development and pledging to globally combat its effects, world leaders have effectively raised the much needed awareness of society as a whole towards the importance of worldwide solidarity against NCDs. ${ }^{9}$

It is difficult to find a country that does not already have a national diabetes plan, which underscores the enormity of the global concern surrounding it. However, many nations among those with lower incomes lack proper funding and implementation of such plans and policies. The WHO Global Action Plan for Prevention and Control of $\mathrm{NCDs}^{8}$ outlines six specific objectives and recommends effective policies for achieving those objectives and ultimately attaining the NCD prevention and control targets set by the Global Monitoring Framework. These objectives are: (1) to prioritize (to a greater extent) NCD prevention and control in global, regional, and national agendas and internationally agreed development goals; (2) to strengthen the national capacity in order to enhance national response for NCD prevention and control; (3) to create, sustain and expand health-promoting environments to reduce modifiable risk factors (namely tobacco use, diet, physical activity and alcohol abuse); (4) to strengthen and orient the health systems to address NCDs through people-centered primary healthcare and universal health coverage; (5) to promote high quality research and development; and (6) to monitor trends and determinants and evaluate progress. By adopting these policies and tailoring them to their population's needs, nations can move a step closer to tackling NCDs, and among them diabetes.

As one of the countries in the Eastern Mediterranean Region, the world's fastest growing hub of diabetes, Iran is a country of 78.8 million population with the second largest economy in the Middle East (after Saudi Arabia), and an estimated GDP of US\$393.7 billion, categorizing it as an upper middleincome country. ${ }^{10}$ The current life expectancy in Iran is 74 years, with 64 years healthy life expectancy. ${ }^{11}$ The greatest burden of disease, as calculated by disability-adjusted lifeyears (DALYs) is attributed to cardiovascular disease and diabetes. NCDs in general are responsible for $76 \%$ of total deaths in the country, with diabetes and cardiovascular disease directly responsible for at least $48 \%$ of total deaths. ${ }^{11}$ A large portion of the deaths caused by diabetes may be prevented by better control of the condition, which relies on increasing awareness and compliance among the patients and advocating self-care, areas in which many Iranian patients are sorely lacking. The Iranian government has long recognized the nation's vulnerability to NCDs and numerous national plans, programs and policies have been implemented over the years with little effect on reducing NCD burden. To effectively overcome this burden, specific and clear policies are needed not only to prevent diabetes, but also to optimize diabetic patients' control; this can be achieved by developing national and local guidelines and auditing their use and misuse on regular basis, as well as holding healthcare professionals responsible when targets are not met.

Following the WHO's call for global action against NCDs, an Iranian National Committee for NCD Prevention and Control was formed, chaired by the Minister of Health and Medical Education (MoHME), and adopted by the Supreme Council of Health and Food Security, which is a multidisciplinary council including 3 vice-presidents and 10 ministers across the government. The national committee is a policy-making, regulatory, scientific, and planning committee that has subcommittees to perform its duties in all areas related to the control of NCDs and risk factors; the committee is regarded as a decision-making body of the MoHME with respect to NCDs. This committee has produced the first National Action Plan for the prevention and control of NCDs, ${ }^{12}$ which includes the voluntary targets set by the Global Monitoring Framework and goes a step further by adding 4 new targets that are specific to national circumstances: zero trans fatty acid in food products, $20 \%$ relative reduction in mortality due to traffic injuries, $10 \%$ relative reduction in mortality due to drug abuse, and $20 \%$ increase in access to treatment for mental diseases. The Action Plan has also changed the targets for reducing physical inactivity from $10 \%$ to $20 \%$ and expansion of preventive cardiovascular treatment to at least $70 \%$ instead of the WHO's proposed $50 \%$ of eligible population. ${ }^{12}$

The Iranian National Action Plan for the Prevention and Control of NCDs sets out ambitious targets and specific recommendations for attaining those targets. Whether implementing the program and its related policies will be feasible and/or effective in the nation's war against NCDs remains to be seen. There are undoubtedly numerous obstacles hindering the achievement of these targets, not least of which is securing the required financial resources needed in an era of resilient economy, as well as the need for safeguarding peoples' health and well-being in the postsanctions Iran, where further Westernization threatens to increase the prevalence of NCD risk factors. Ambitious targets, limited resources and rising risk factors; these entities summarize the challenge of facing NCDs not only in Iran, but in every developing nation around the globe. Therefore, how Iran goes forward and what it achieves from adopting and building on the United Nations Development Programme (UNDP), WHA, and WHO agendas for tackling NCDs will undoubtedly be of immense educational value not only to its neighboring countries, but to the broader global community.

Ethical issues

Not applicable.

Competing interests

Authors declare that they have no competing interests.

Authors' contributions

AT conceived the manuscript and contributed to content and revisions. SKA contributed to writing, content, and revisions of the manuscript.

\section{Authors' affiliations}

'Department of Global Health and Public Policy, School of Public Health, Tehran University of Medical Sciences, Tehran, Iran. ${ }^{2}$ Department of Health Management and Economics, School of Public Health, Tehran University of Medical Sciences, Tehran, Iran. ${ }^{3}$ College of Health and Life Sciences, Brunel University London, Uxbridge, UK. ${ }^{4}$ Diabetes Research Center, Endocrinology 
and Metabolism Research Institute, Tehran University of Medical Sciences, Tehran, Iran.

\section{References}

1. World Health Organization (WHO). Global Report on Diabetes. http://apps.who.int/iris/bitstream/10665/204871/1/9789241565257_ eng.pdf. Published 2016

2. Countries in the world by population (2016). Worldometers website. http://www.worldometers.info/world-population/population-bycountry/.

3. Danaei G, Finucane MM, Lu Y, et al. National, regional, and global trends in fasting plasma glucose and diabetes prevalence since 1980: systematic analysis of health examination surveys and epidemiological studies with 370 country-years and $2 \cdot 7$ million participants. Lancet. 2011;378(9785):31-40. doi:10.1016/ s0140-6736(11)60679-x

4. Aguiree F, Brown A, Cho $\mathrm{NH}$, et al. IDF diabetes atlas. http:// www.idf.org/sites/default/files/EN_6E_Atlas_Exec_Sum_1.pdf. Published 2013

5. NCD Risk Factor Collaboration. Worldwide trends in diabetes since 1980: a pooled analysis of 751 population-based studies with 4. 4 million participants. Lancet. 2016;387(10027):15131530. doi:10.1016/s0140-6736(16)00618-8

6. Seuring T, Archangelidi $O$, Suhrcke M. The economic costs of type 2 diabetes: a global systematic review. Pharmacoeconomics.
2015;33(8):811-831. doi:10.1007/s40273-015-0268-9

7. World Health Organization (WHO). Monitoring framework and targets for the prevention and control of NCDs: a comprehensive global monitoring framework, including indicators, and a set of voluntary global targets for the prevention and control of non communicable diseases. http://www.who.int/nmh/events/2012/ ncd_discussion_paper/en/. Accessed September 6, 2012. Published 2012.

8. World Health Organization (WHO). Global action plan for the prevention and control of noncommunicable diseases 20132020. http://www.who.int/nmh/events/ncd_action_plan/en/. Published 2013.

9. Resolution adopted by the General Assembly SSAia. Transforming our world: the 2030 Agenda for Sustainable Development. Published September 25, 2015.

10. World Bank 2015. http://www.worldbank.org/en/country/iran. Accessed April 15, 2016.

11. World Health Organization (WHO). Non-communicable Disease Country Profiles. http://www.who.int/nmh/publications/ncdprofiles-2014/en/. Published 2014.

12. Iranian National Committee for NCD Prevention and Control. National Action Plan for Prevention and Control of NonCommunicable Diseases and the Related Risk Factors in the Islamic Republic of Iran, 2015-2025. 2015. 